\title{
Reassessing the Curriculum-Competency Alignment in MBA Programs
}

\author{
Prof. Kamal Kishore Jain \\ Area Chair, Organizational Behavior and HRM, IIM Indore \\ Indian Institute of Management Indore, Rau - Pithampur Road, Indore 453331, India \\ Tel:+91-731-2439515 E-mail:kamal@iimidr.ac.in \\ Kumar Kunal Kamal (Corresponding author) \\ Doctoral Student, Organizational Behaviour and HRM, IIM Indore \\ Indian Institute of Management Indore, Rau - Pithampur Road, Indore 453331, India \\ Tel: +91-(0)-9907668342Ｅ-mail: f07kunalk@iimidr.ac.in
}

Received: August $24 \quad$ Accepted: September 7 doi:10.5430/jms.v1n1p68

\begin{abstract}
The paper seeks to assess the alignment between the focus of the MBA curricula and the managerial competencies required on the job, across two different nations: India and USA. The data for the study was gathered by visiting the website of business schools which were ranked on the basis of the placement figures as reported by the surveys done by Wall Street Journal (b-schools in India) and Financial Times (b-schools in USA). The b-schools were grouped into three categories: Top tier b-schools and second tier b-schools from India, and top tier b-schools from USA. The core courses in the MBA programs were identified and coded to fall under distinct competency categories. Data was coded with high intercoder reliability and put through statistical tests to draw conclusions. The study found that there indeed is a misalignment between required course curriculum and managerial competencies across the three groups of business schools, and that there is no difference in the required curricula across different tiers of b-schools. It was also found that no correlation exists between average salary offerings and the required curricula.
\end{abstract}

Keywords: MBA program, Required curricula, Core courses, Managerial competencies

\section{Introduction}

Researchers and practitioners alike have raised the issue of the misalignment between the competencies which the MBA curriculum attempts to impart and the competencies which the managers need while on job (Anwar, Al-Shami, \& Ahmed, 2006; Blass \& Weight, 2005; Elliott \& Goodwin, 1994; Gupta, Saunders, \& Smith, 2007; Kleiman \& Kass, 2007; Rubin $\&$ Dierdorff, 2009). While issues like the need to include new and integrative courses have been raised along with curriculum innovation (Navarro, 2008), program design and pedagogical changes too have attracted the attention of critics (Buchowicz \& Buchanan, 2008; Dumas, Blodgett, Carlson, Pant, \& Venkatraman, 2000). In light of sharp criticisms on the role played by business school graduates in corporate scandals, and the alleged lack of courses that develop the powers of critical thinking and moral reasoning (Podolny, 2009), business schools have introduced changes to the curriculum and teaching methods, albeit to a smaller extent. The changes in business curricula, like the inclusion of courses on Ethics in business schools curricula, it is argued, should not only be a wishful thinking but a compulsory requirement so that the managers of tomorrow should understand and value their ethical responsibilities to society (Evans, Treviño, \& Weaver, 2006; Swanson, 2004). Authors have also argued for a shift in favor of Human-Centered Curriculum in business education (Giacalone \& Thompson, 2006). In a recent study, Bell et al. (2009) cite moral, ethical, and business reasons for mandatory diversity education so that the management students are well-equipped to participate in diverse environments. Researchers have also reasoned that the curriculum "must be infused with multidisciplinary, practical, and ethical questions and analyses reflecting the complex challenges business leaders face" (Bennis \& O'Toole, 2005). All in all, there is enough discussion both by researchers and practitioners alike wherein the relevancy of business school curricula and its alignments with managerial competencies needed on the job are called into question.

The present study is based on a recent study by Dierdorff et al. (Dierdorff, Rubin, \& Morgeson, 2009) and Rubin and Dierdorff (2009) wherein the authors highlighted the misalignment between the focus of the MBA curricula and the 
managerial competencies required on the job. While Dierdorff et al. (2009) relied on an empirically derived competency model from 8,633 incumbent managers across 52 managerial occupations to arrive at a set of required managerial competencies, Rubin and Dierdorff (2009) examined the relevancy of the MBA curricula in relation to managerial competency requirements. Across 373 schools, the most critical managerial competencies were found to be the very competencies least represented in MBA curricula, hence a 'misalignment' between curriculum and competencies.

\subsection{Research Questions}

The present study tries to reassess the curriculum-competency alignment in MBA programs across two different nations: India and USA, and tries to examine if there is any relation between Average Salary Offered and the Required Curricula. There are three specific research questions that the present study tries to answer:

Research Question (1): In light of the studies and their outcomes, does the 'misalignment' between required curricula and required managerial competencies stands true in the Indian context?

Research Question (2): Is there any difference in the required curricula offered by different Tiers of b-schools in India and US?

Research Question (3): Is there any correlation between average salary offerings and the required curricula?

\section{Methodology}

\subsection{Dataset Used}

Data regarding the required academic curriculum of the various b-schools was collected from the website of the respective b-schools. Based on the b-school rankings on the basis of 'Average Salary Offered', top 60 b-schools were selected in the Indian context and top $30 \mathrm{~b}$-schools from the USA. The $60 \mathrm{~b}$-schools in the Indian context were further divided into two equal halves to come up with the following Dataset: a) Group 1 representing 30 Top Tier b-schools in the Indian context; b) Group 2 representing 30 Second Tier b-schools in the Indian context; c) Group 3 representing 30 Top Tier b-schools in the American context.

\subsection{Measures}

The b-schools were selected on the basis of the rankings based on available placement figures as reported by surveys done by Wall Street Journal (b-schools in India) and Financial Times (b-schools in USA). Only those b-schools providing a Two Year Full Time MBA (or its equivalent) Course were considered. Those b-schools which did not provide sufficient information about their MBA curricula on their website were not included in the study (Note 1). In addition, only 'Required Core-Courses' in the First Year of Study were studied. It might be noted that the required core-courses are those courses which are covered in the first year of study and are introductory in nature covering many different fields (Segev, Raveh, \& Farjoun, 1999). Although introductory, every student is expected to go through them. To generate a list of core-courses, the websites of the business schools were visited and information related to the courses was retrieved. A total of 1605 core courses were identified. The next task was to classify each course as belonging to one of the Competency Category identified (MDP, MHC, etc.) in Dierdorff et al. (2009) study (for a list of examples of classified courses, please refer Table I).

$<$ Table 1about here>

The authors were free to mark the courses as falling under 'unclassified' category in case the courses did not fall in any of the categories identified by Dierdorff et al. (2009). To put objectivity in the classification process, the authors of this paper independently reviewed and coded the courses with 95.6 percent absolute agreement. In cases of disagreement, a consensus was achieved or the courses were put in the unclassified category; the percentage of such courses stood at a statistically low value of 3.6 percent.

\section{Results and Analysis}

The first research question was answered by comparing the Actual Percentage Value of each competency category to the Benchmark Percentage Value. Table II and Figure 1 show the pattern of curricular alignment:

\section{$<$ Table 2 about here $>$ \\ $<$ Figure 1 about here $>$}

The figure confirmed that there indeed is a 'misalignment' between required course curriculum and managerial competencies. To probe further, and to answer the rest two research questions, the following Hypotheses were constructed (while Hypotheses 1A to $1 \mathrm{G}$ helped answer the second research question, Hypothesis 2 helped answer the third research question). 
Hypotheses 1(A)-1(G):

Hypothesis 1(A): There is no significant difference in the 'Overall Course Curriculum' offered by the three different groups of b-schools;

Hypothesis 1(B): There is no significant difference regarding focus on 'Managing Decision Making Processes' in the required course curriculum offered by the three different groups of $b$-schools;

Hypothesis $1(C)$ : There is no significant difference regarding focus on 'Managing Human Capital' in the required course curriculum offered by the three different groups of b-schools;

Hypothesis 1(D): There is no significant difference regarding focus on 'Managing Strategy \& Innovation' in the required course curriculum offered by the three different groups of b-schools;

Hypothesis 1(E): There is no significant difference regarding focus on 'Managing Task Environment' in the required course curriculum offered by the three different groups of b-schools;

Hypothesis 1(F): There is no significant difference regarding focus on 'Managing Administration and Control' in the required course curriculum offered by the three different groups of $b$-schools;

Hypothesis $1(G)$ : There is no significant difference regarding focus on 'Managing Strategy \& Innovation' in the required course curriculum offered by the three different groups of b-schools

To test Hypotheses 1 (A) to 1 (G) first the Euclidean Distance-Squared Estimates across the three groups of b-schools were measured, and then One-Way ANOVA with Tukey Multiple Comparison Test was applied to analyze and examine the differences regarding focus on the competency categories among the three different sets of Business Schools.

To calculate the Root Euclidian Distance Squared Values, first the number of courses falling under the different classifications was converted to Percentage Values. Then, these percentage values were subtracted from the '\% Coverage Benchmark' used in Rubin and Dierdorff's (2009) study. This way the Euclidean Distance between the 'Benchmark Percentage' and the 'Actual Percentage' was calculated. The values of the Euclidean Distance were then squared and put under-root value to arrive at the Modal Value of Euclidean Distance, thus yielding the Root Euclidean Distance Squared Value.

Finally, the Hypotheses 1A-1G were tested through One-Way ANOVA with Tukey Multiple Comparison Test; the significance level was put at 0.05 . The results failed to reject all the Null Hypotheses except 1 (D). Post Hoc analysis based on Tukey's HSD helped understand that there are significant differences regarding focus on 'Managing Strategy \& Innovation' among all the groups. While there is little emphasis on the courses related to 'Managing Strategy \& Innovation' in the Indian context as compared to the US context, in Second Tier b-schools in India the focus is even lesser.

Hypothesis 2: "There is no correlation between required course curriculum and average salary offered".

Hypothesis 2 was tested through Pearson Correlation Analysis between Required Course Curriculum (RCC) and Average Salary Offered (ASO). The value of RCC for every school was calculated by summing up the Root Euclidean Distance Squared Value for each competency category. To calculate the value of ASO, the salaries offered were converted into percentage figures to make analysis easier and comparable across groups. The conversion was carried by dividing the ASO value of a business school ' $x$ ' by the sum total value of the ASO values of all the 30 business schools in that group. The final value arrived was finally multiplied by a factor of 100 to arrive at the percentage figure. Bivariate Correlation between RCC and ASO was found out with Pearson Correlation Coefficient with Two-tailed Test of Significance.

No significant correlation was found between RCC and ASO (correlation value of 0.114 with significance value of 0.284), entailing that there is no correlation between Required Course Curriculum and Average Salary Offered to MBA students.

\section{Discussion}

\subsection{Is the Misalignment Real?}

Although the results of this study clearly show the misalignment between the competencies required and the competencies imparted, one may argue that there is a difference between what the businesses say they want (in terms of competencies required) and what they really want! In a carefully crafted study, Rynes et al. (2003) found a marked difference between what recruiters said they were looking for and between what they would ultimately select for: the authors found out that the recruiters make selection decisions on the basis of possession of technical skills. The focus on possession of technical skills, and too much focus on the development of knowledge and skills relevant for the job, has 
put immense pressure on faculty and a misplaced responsibility to teach only 'relevant' courses (Kleiman \& Kass, 2007). This is one of the biggest challenges that the business schools' faculty face today; the problem is more in terms of their own identity: are they trainers or teachers? The identity of business schools can be questioned as well: are the business schools, schools of learning or training centers? As Pfeffer and Fong (2002) state, it is by explicitly rejecting the trade-school model that business schools have gained respectability and the present status. As obvious, there is no use going back to where we started.

\subsection{Focus on Analytical Skills}

The data shows that there is an overemphasis on the development of analytical skills in the MBA curricula. One reason behind the focus of the curricula on teaching mastery of analytical tools and techniques could be the attempt of business to gain control of professional knowledge by commodifying it (Trank \& Rynes, 2003); as courses that focus on analytic skills could help in this endeavor, the non-technical courses that impart soft skills or deal with social topics would obviously take a beating. The overemphasis on development of analytical skills at the expense of interpersonal skills and an ability to integrate and develop wisdom has also been underlined by researchers like Pfeffer and Fong (2002). Pfeffer and Fong (2002) have questioned the impartation of these skills and their value by arguing that these skills can be learned by any intelligent person without the need for her/his attending to any business school; they reason that instead the focus should be on development of interpersonal and leadership skills so that the students don't only learn to talk about business, but also learn about business.

The focus on development of analytical skills could also be gauged from the data - courses which focus on development of analytical skills, viz. MTE, MAC, and MLT get much higher focus when compared to '\% Coverage Benchmark' in both Indian as well as US context albeit with the exception of MLT: business schools in the Indian contexts focus a lot more on MLT whereas their counterparts in the US context focus close to the '\% Coverage Benchmark', in fact, lesser than the benchmark. One reason behind this difference could be the acute shortage of skilled professionals in the logistics sector at all levels in the Indian context (Dubey \& Singh, 2009; KPMG, 2007).

Another important point to note is the fact that while the b-schools seem to focus a lot on development of analytical skills, when it comes to teaching statistical techniques the focus is weak; that too when statistical methods are considered important in various functional areas of management and help the managers in decision making processes (Stray, Naude, \& Wegner, 1994; Tamura, 2007). As the data suggests, the focus on teaching courses that fall in the category 'Managing Decision-Making Processes' is lower in both Indian as well as the US context when compared to the ' $\%$ Coverage Benchmark'. This also reflects the findings by McAlevey et al. (2001) that statistics does not hold the high ground in the business schools. While the business schools are keen on teaching other analytical techniques, the lesser focus on statistical techniques is surprising; one of the reasons could be the lack of time and knowledge on part of the business school faculty (Stray et al., 1994). Another reason could be the nature of responsibility for instructors on teaching courses in statistics: as argued by McAlevey et al. (2001), in business schools statistics courses are in most cases taught by instructors whose primary interests lie in other areas of management.

\subsection{Resistance to Change}

Focusing on the reason behind the misalignment, it could be argued that the reason behind the 'misalignment' could be the ubiquitous fear and the threatening nature of changes (Kleiman \& Kass, 2007). Thus changes even if needed, would be slow in nature and it would be better that they be slow, so that the friction could be minimized. Also, the business schools have limited pool of resources and it would take a decent period of time before it can use those resources to affect new changes. Quick and flying changes might even destroy the basic foundation on which we want our changes to take place - we must be wary of this fact and thus take only judicial and well thought of steps; else we shall end up with burnt fingers and broken hearts.

Also, one of the reasons behind preferring a 'No Change' position might be a desire to satisfy the needs and desires of the institutional actors in the field of business education. Trank and Rynes (2003) have identified five such institutional actors which share an interest in the business education. Any change might come in conflict with the goals and objectives of these institutional actors and may lead to an unfavorable situation which the business schools might prefer to avoid by taking stance against any proposed change in the curricula.

Another view of looking at the misalignment could be the argument that there is no need to change! It can be argued that it has become a fancy in the modern world to keep on criticizing the b-schools: suddenly everyone has become interested and competent enough to criticize the functioning of the business schools, the curricula, the selection process, and what not! We need to be wary of those elements who criticize because they are the players of what they might perceive as a zero-sum game with b-schools as their competitors, players, who, as Weick (2003) identifies want to 
"make their real world, our real world". Nonetheless, it is real good that at least in the important journals, newsletters, and many other places, management education is getting criticized and debated. It is a positive sign, but at the same time a critical situation, as any wrong step would seriously jeopardize our future as a professional education stream. Good that we have started repairing our roads, but let us not lose the direction, that is more important - let there be changes, but let them be for good.

\section{Limitations}

\subsection{Single Ranking Parameter}

Although ranking parameters and ranking as a whole has been widely criticized mainly because it has led to investment of the limited resources that business schools have, in image-related features at the cost of substantive program enhancements (Corley \& Gioia, 2000; Gioia \& Corley, 2002), it is a parameter which is hard to ignore (Dahlin-Brown, 2006). As rankings can be easily fiddled by changing the weights of the factors included in the ranking criteria (Stake, 2006), and there can be multiple reasons behind fiddling up with the factors and the weights, this paper uses only one factor 'placement figures' as they can be readily seen as the evaluation of the business schools and their curricula by the corporate world.

\subsection{MBA as an Experience}

The present study is also limited in the sense that it has only tried to analyze the course contents and has not touched upon the other aspects where the participants may learn and acquire different skills, after all MBA is not just a program, but an experience in itself. In a recent study by Hay and Hodgkinson (2008), the authors found out that the MBA program has much to offer than the analytical skills considered relevant for the target jobs. Hay and Hodgkinson's (2008) study points out three broad outcomes of the MBA studies, viz. a) Broadening of perspectives; b) Increased positive feeling towards self; and c) Formal learning (tools, techniques, and theories). The study also points out that the "sharing of experiences', an integral part of the MBA experience helps in increasing the complexity of manager's thinking. While criticizing the business schools for not focusing enough on courses that help develop competencies like Management of Decision-Making Processes and Management of Human Capital, we might be demanding too much from the MBA Programs. It might be the case that these courses do not get a reflection in the curricula, but are very much part of the MBA experience.

\subsection{Pedagogical Issues}

Although what is being taught is important, but what is even more important is how the course is taught: merely looking at the course content would not tell us the reflective attitude and the experimental pedagogies applied in the classroom. Take for example, the teaching of Leadership, while the presence of such a course in the MBA curricula would signal that the business school is focusing on the development of competencies which would help the student mange human capital in a better way, the signal might be deceiving. Gabriel (2005) rightly argues that the "structure, ideology and ethos of MBA programmes are fundamentally opposed to an education of leaders" and that MBA programs can best instill a sense of disciplined and committed followership and not great leaders. Nonetheless, the pedagogies applied can definitely make some difference and can help develop competencies which are otherwise hard to develop in MBA classroom. A good example could be Sinclair's (2007) experimentation, in which students would not only learn the skills but would also involve themselves in practicing, taking part in experiments, and thus learn from the outcomes. The increasing use of application based pedagogical techniques in the classroom would also help the faculty in equilibrating the theory-application wavering by demonstrating the application of management theories while focusing on theory in their own instruction (Wren, Halbesleben, \& Buckley, 2007).

Lessons can also be learnt from seemingly unrelated fields, as Volkmann and De Cock (2007) try: by critically analyzing the principles on which the Bauhaus School stood and the problems it faced; the authors provide new textures to the debate on the future of the business schools. The authors do not offer any clear cut solutions but their analysis does provide a deeper understanding of the pedagogical tools which Bauhaus School applied and the challenges that the school faced.

\section{Future Direction}

The results of the study confirm that the 'misalignment' between the required course curriculum and the managerial competencies are there in the Indian context as well. The present study goes one step ahead of earlier studies by correlating the curricula with the salary offerings and shows that no significant curricula-salary correlation exists. Nonetheless, the scope of the present study can be increased by focusing on a wider context (ex: Asian context). Also, a more fundamental study focusing on the competency and work role requirements in local contexts would help find if the set of managerial competencies identified by Dierdorff et al. (2009) are universally viable. 


\section{References}

Anwar, S. A., Al-Shami, M., \& Ahmed, S. A. (2006). Developing a market-oriented MBA program: Practitioners' views from the GCC countries. Journal of International Marketing \& Marketing Research, 31(3), 129-139.

Bell, M. P., Connerley, M. L., \& Cocchiara, F. K. (2009). The case for mandatory diversity education. Academy of Management Learning \& Education, 8(4), 597-609.

Bennis, W. G., \& O'Toole, J. (2005). How business schools lost their way. Harvard business review, 83(5), 96-104.

Blass, E., \& Weight, P. (2005). The MBA is dead-part 1: God save the MBA! On the Horizon, 13(4), 229.

Buchowicz, B. S., \& Buchanan, J. (2008). Level four MBA program design. Journal of Business and Behavioral Sciences, 19(2), 58-66.

Corley, K., \& Gioia, D. (2000). The rankings game: Managing business school reputation. Corporate Reputation Review, 3(4), 319-333.

Dahlin-Brown, N. (2006). The perceptual Impact of U.S. news \& world report rankings on eight public MBA programs. Journal of Marketing For Higher Education, 15(2), 155-179.

Dubey, R., \& Singh, T. (2009). Study on logistics skill gap in supply chain sector in India-empirical findings. AIMS International Journal of Management 3(3), 191-205.

Dumas, C., Blodgett, M., Carlson, P., Pant, L., \& Venkatraman, M. (2000). Revitalizing the MBA for the new millennium: A collaborative action research approach. International Journal of Value-Based Management, 13(3), 229-253.

Elliott, C. J., \& Goodwin, J. S. (1994). MBA programs and business needs: Is there a mismatch? Business Horizons, 37(4), 55.

Evans, J. M., Treviño, L. K., \& Weaver, G. R. (2006). Who's in the ethics driver's seat? Factors influencing ethics in the MBA curriculum. Academy of Management Learning \& Education, 5(3), 278-293.

Gabriel, Y. (2005). MBA and the education of leaders: The new playing fields of eton? Leadership, 1(2), 147-163.

Giacalone, R. A., \& Thompson, K. R. (2006). Business ethics and social responsibility education: Shifting the worldview. Academy of Management Learning \& Education, 5(3), 266-277.

Gioia, D. A., \& Corley, K. G. (2002). Being good versus looking good: Business school rankings and the circean transformation from substance to image. Academy of Management Learning \& Education, 1(1), 107-120.

Gupta, P., Saunders, P., \& Smith, J. (2007). Traditional master of business administration (MBA) versus the MBA with specialization: A disconnection between what business schools offer and what employers seek. The Journal of Education for Business, 82(6), 307-312.

Hay, A., \& Hodgkinson, M. (2008). More success than meets the eye-a challenge to critiques of the MBA: Possibilities for critical management education? Management Learning, 39(1), 21-40.

ierdorff, E. C., Rubin, R. S., \& Morgeson, F. P. (2009). The milieu of managerial work: An integrative framework linking work context to role requirements. Journal of Applied Psychology, 94(4), 972-988.

Kleiman, L. S., \& Kass, D. (2007). Giving MBA programs the third degree. Journal of Management Education, 31(1), 81-103.

KPMG. (2007). Skill gaps in the Indian logistics sector: A white paper.

McAlevey, L., Everett, A. M., \& Sullivan, C. (2001). Evolution in business statistics curricula: Learning from the 'making statistics more effective in schools of business' conference. Journal of the Royal Statistical Society: Series D (The Statistician), 50(3), 321-333.

Navarro, P. (2008). The MBA core curricula of top-ranked U.S. business schools: A study in failure? Academy of Management Learning \& Education, 7(1), 108-123.

Pfeffer, J., \& Fong, C. (2002). The end of business schools? Less success than meets the eye. Academy of Management Learning and Education, 1(1), 78-95.

Podolny, J. M. (2009). The buck stops (and starts) at business school. Harvard business review, 87(6), 62-67.

Rubin, R. S., \& Dierdorff, E. C. (2009). How relevant Is the MBA? Assessing the alignment of required curricula and required managerial competencies. Academy of Management Learning \& Education, 8(2), 208-224. 
Rynes, S. L., Trank, C. Q., Lawson, A. M., \& Ilies, R. (2003). Behavioral coursework in business education: Growing evidence of a legitimacy crisis. Academy of Management Learning \& Education, 2(3), 269-283.

Segev, E., Raveh, A., \& Farjoun, M. (1999). Conceptual maps of the leading MBA programs in the United States: Core courses, concentration areas, and the ranking of the school. Strategic Management Journal, 20(6), 549-565.

Sinclair, A. (2007). Teaching leadership critically to MBAs: Experiences from heaven and hell. Management Learning, $38(4), 458-472$.

Stake, J. E. (2006). The Interplay between law school rankings, reputations, and resource allocation: Ways rankings mislead. Indiana Law Journal, 81(1), 229-270.

Stray, S., Naude, P., \& Wegner, T. (1994). Statistics in management education. British Journal of Management, 5(1), 73.

Swanson, D. L. (2004). The buck stops here: Why universities must reclaim business ethics education. Journal of Academic Ethics, 2(1), 43-61.

Tamura, H. (2007). Foundational value of statistics education for management curriculum. International Statistical Review, 75(3), 397-405.

Trank, C., \& Rynes, S. (2003). Who moved our cheese? Reclaiming professionalism in business education. Academy of Management Learning and Education, 2(2), 189-206.

Volkmann, C., \& De Cock, C. (2007). The Bauhaus and the business school: Exploring analogies, resisting imitation. Management Learning, 38(4), 389-403.

Weick, K. E. (2003). Commentary on Czarniawska. Management Learning, 34(3), 379-382.

Wren, D. A., Halbesleben, J. R. B., \& Buckley, M. R. (2007). The theory-application balance in management pedagogy: A longitudinal update. Academy of Management Learning \& Education, 6(4), 484-492.

\section{Notes}

Note 1. Details of business schools included in this study can be had from the authors on personal request.

Table 1. Examples of Classified MBA Courses

\begin{tabular}{|l|l|}
\hline Examples of Classified MBA Courses* & Classified Course Examples \\
\hline Competency Category & $\begin{array}{l}\text { Managerial Decision Analysis; Decision Models; } \\
\text { Applied Statistical Analysis; Managerial Statistics; } \\
\text { Quantitative Methods }\end{array}$ \\
\hline Managing Decision-Making Processes (MDP) & $\begin{array}{l}\text { Organizational Behavior; Human Resource } \\
\text { Management; Leadership Dynamics; Organizational } \\
\text { Theory; Negotiation; Managerial Effectiveness }\end{array}$ \\
\hline Managing Human Capital (MHC) & $\begin{array}{l}\text { Strategic Planning; Strategy Implementation; } \\
\text { Strategic Analysis; Competitive and Corporate } \\
\text { Strategy }\end{array}$ \\
\hline Managing Strategy \& Innovation (MSI) & $\begin{array}{l}\text { Marketing Management; Managerial Economics; } \\
\text { Macroeconomic Policy; Globalization of Business; } \\
\text { International Economics }\end{array}$ \\
\hline Managing Administration \& Control (MAC) & $\begin{array}{l}\text { Managerial Accounting; Financial Analysis; } \\
\text { Contemporary Business Law; Corporate Finance; } \\
\text { Business Policy; Cost Analysis }\end{array}$ \\
\hline Managing Logistics \& Technology (MLT) & $\begin{array}{l}\text { Operations and Supply Chain Management; } \\
\text { Management Information Systems; Production and } \\
\text { Operations Management; Operations Management }\end{array}$ \\
\hline $\begin{array}{l}\text { *Source: Rubin, R.S. \& Dierdorff, E.C. (2009), "How Relevant Is the MBA? Assessing the Alignment of } \\
\text { Required Curricula and Required Managerial Competencies", Academy of Management Learning \& } \\
\text { Education, Vol. 8 No. 2, pp. 208-224. }\end{array}$ \\
\hline
\end{tabular}


Table 2. Pattern of curricular alignment

\begin{tabular}{|l|l|l|l|l|l|l|}
\hline & MDP & MHC & MSI & MTE & MAC & MLT \\
\hline Group 1 (Tier I India) & 13.89 & 14.66 & 3.34 & 26.55 & 22.29 & 16.61 \\
\hline Group 2 (Tier II India) & 14.05 & 16.93 & 0.69 & 26.73 & 20.30 & 17.41 \\
\hline Group 3 (Tier I USA) & 15.35 & 14.56 & 7.87 & 26.86 & 21.66 & 9.81 \\
\hline \% Coverage Benchmark & 19.66 & 19.01 & 17.14 & 17.02 & 16.55 & 10.61 \\
\hline
\end{tabular}

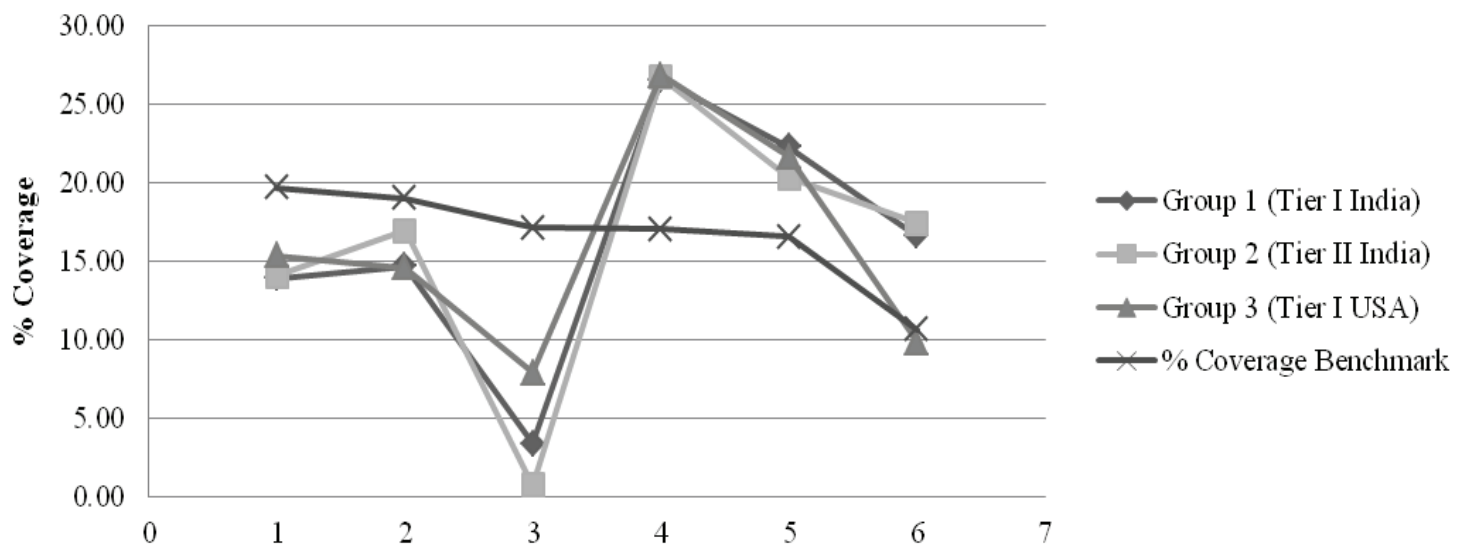

Figure 1. Pattern of Curricular Alignment 